\title{
Lessons from the Self-organization Concept for Ore Forming Processes and Mineral Resources
}

\author{
DIETRICH, S. ${ }^{123}$
}

${ }^{1}$ Department of Earth Science, Technical University Berlin, Alumna, sabine.dietrich@alumni.tu-berlin.de

Mineral deposits and ore bodies in the earth's crust often display rhythmic patterns such as banded formations, layered and folded structures, diapirs or cockade ores that range in size from just a few millimetres to several kilometres.

We proposed applying the concept of selforganization to mineral deposits. Recognizing mineral deposits and ore bodies as ordered structures allows them to be considered as a system in which their components and properties are distributed in space and time. This perspective leads to fundamental aspects of understanding mineral deposits and ore genesis.

The concept was tested by examining a recent early diagenetic banded iron-manganese mud in an abandoned underground mine with a precipitation that had accumulated over 40 years. More than two years of in-situ monitoring revealed that the self-organizing nature of the precipitated material was not only influenced by external fluctuations but also caused internally by redox, colloid, microbial, electrical and Ostwald-ripening processes. A genetic model for the banded mineralization was developed and successfully verified by numerical simulation.

In addition, gradients, such as concentration gradients, electric fields and the like, as well as temperature and pressure, enable a coupling of the ongoing processes that is spatially and temporally farreaching.

This new thinking could lead to new insights into the emergence of mineral resources in the earth's crust, seen as part of the complex system Earth, if the current ideas on the genesis of banded and other structures in hydrothermal, magmatic, metamorphic, sedimentary, and supergene ore bodies and systems are reconsidered. 